\title{
Local development using social capital as an instrument: a comparative analysis
}

\author{
P. Karametou \& C. D. Apostolopoulos \\ Department of Home Economics and Ecology, \\ Harokopio University of Athens, Greece
}

\begin{abstract}
This study aims to present the process for the development of a social capital measurement tool, which was adapted to the Greek socio-cultural context. The validity and the reliability of this social capital questionnaire were evaluated in a sample of 318 adults drawn from two different mountain rural areas in Greece. The social capital questionnaire is a useful instrument in measuring the existent stock of social capital and in understanding the local development "physiognomy" of two Greek mountainous rural areas. However, we should keep in mind that the reliability of responses to questionnaires is always questionable, in particular for subjective questions about social norms. This is why detailed interviews constitute a precious tool to corroborate the results of a survey. For this reason, the present survey was subsequently followed up by 46 in-depth, semi-structured interviews with selected participants in both areas. The overall socio-economic status of the two case study areas was assessed in relation to a wide variety of social capital related variables. Using the data collected from the quantitative research, the paper describes how social capital is distributed geographically between the two different mountain areas. On the whole, both case study areas appear not to be substantially different in aggregate levels of social capital. Therefore, social capital seems to be different in its characteristics and underlying structure in both case study areas.
\end{abstract}

Keywords: local development, social capital, mountain rural areas, Greece.

\section{Introduction}

Social capital is not a single entity, but is rather multi-dimensional in nature. The definition of social capital dimensions used varies considerably from one study 
to another. This lack of clarity can be partly explained by the variety of disciplines that have examined the concept. Woolock differentiates between "bonding" social capital and "bridging" social capital and asserts that without the latter; communities do not have what is needed to "get ahead". Put simply, one can distinguish three major approaches of social capital (Woolock [1]). The micro-approach focuses on the nature and forms of co-operative behaviour, the macro-approach focuses on the conditions for co-operation and the mesoapproach highlights structures that enable co-operation to take place. After an overview of the literature and drawing on the work of James Coleman and Robert Putnam and others we can say that the main dimensions of social capital are six: group and networks; trust and solidarity; collective action and cooperation; information and communication; social cohesion and inclusion; and empowerment and political action (e.g. Grootaert and Van Bastelaer [2]; Grootaert and Van Bastelaer [3]; Grootaert [4]; Ibáñez et al. [5]; Narayan and Cassidy [6]; Narayan and Pritchett [7]; World Bank [8]). From this analysis, a set of specific items was designed to provide (partial) empirical tests of the theoretical components of social capital.

The relationship between social capital and socio-economic development constitutes a controversial relation with both positive and negative interconnections and interactions. Putnam argues that social capital and a civil society promote economic growth (Putnam [9]). Furthermore, according to Knack and Keefer much of the economic backwardness in the world can be explained by the existence of a lack of mutual confidence (Knack and Keefer [10]). Moreover, they argue that low levels of trust in a society could probably discourage its processes of innovation. What is very interesting is that societies that are characterized by high levels of trust are also less dependent on formal institutions to enforce agreements. In addition, government officials in societies with higher trust may be perceived as more trustworthy, and their policy declarations are seen as more credible (Knack and Keefer [10]). On the other hand, according to Trigilia, social capital does not have only positive impacts but it can also create obstacles to local development (Trigilia [11]).

Therefore, it is very important, according to the aims of this study, to investigate under what conditions social capital can favour local socio-economic development in Greece. In order to achieve this is necessary to construct first a methodological instrument such as an integrated questionnaire suitable for the measurement of social capital in the specific socio-cultural Greek context and especially in Greek mountainous areas. The main objective of this paper is to validate a social capital measurement tool in order to develop empirical evidence of social capital's association with local development outcomes in two Greek mountainous rural areas. Until this moment there does not exist in Greece such kind of instrument so the development of this is a big challenge. The tool that best served this purpose, and that we used as a pattern, is the social capital questionnaire developed in Australia by the Onyx \& Bullen (e.g. Onyx and Bullen [12]; Kritsotakis et al. [13]). The following two sections present a brief summary of the methodologies used to develop a suitable methodological instrument in order to collect both quantitative and qualitative data for the 
estimation of the structure and the profile of social capital in the mountain areas of Pilion and Zagori, as well as some first findings from the statistical data analysis used in order to check the reliability of the social capital questionnaire. The final section concludes with the key issues revealed by the whole analysis.

\section{Methodology}

\subsection{The study areas}

The research strategy employed in this study consists of two distinctive components: the adoption of a case study approach and the use of both quantitative and qualitative techniques in data collection. Due to the complex nature of the social capital concept, it was decided that the scope of inquiry would be improved by having two different case study areas to provide a more compelling and robust interpretation of the information collected. These areas differed in unemployment rates, population density, real estate value, and percentage of people with a university degree. The Region of Thessaly (the municipalities of Portaria, Zagora, Mouressio, Milies, Argalasti and the commune of Makrinitsa) and the Region of Epirus (the municipalities of Anatoliko Zagori, Kentriko Zagori, Tymfi and the commune of Papigo) were the chosen case study areas for this study. Regarding the first case study area, it is one of those which have adequate resident population and economic sustainability, based on stock farming, forestry, traditional industry, tourist and vocational activities. The second case study area includes the village complex of Zagori. This area tends to become highly isolated, since many inhabitants have migrated to urban areas; it also faces considerable environmental problems such as soil erosion, and insufficient preservation of residential properties and monuments. Zagori is the most mountainous and most isolated area in the region. If, as Coleman and others suggest, social capital is most likely to develop in communities with a strong sense of internal identity and boundary, then it is highly possible that socially isolated and rural communities will demonstrate higher levels of social capital (Onyx and Bullen [12]). However, these communities are also likely to demonstrate more conservative attitudes and intolerance to difference, characteristics also believed to be associated with low levels of social capital (Cox [14]; Putnam [15]). Consequently, the context of this case study provides us with the opportunity to investigate social capital in two different areas that make up a representative sample of the Greek mountainous rural area.

\subsection{Data collection procedures}

A research strategy, which included the use of a locally -based integrated questionnaire, was applied, in order to measure the available stock of social capital and its role in the development of the two areas under study, taking into consideration all seven pairs of dimensions (groups and networks, trust and solidarity, collective action and cooperation, information and communication, 
social cohesion and inclusion, empowerment and political action and social innovation). A draft questionnaire was developed and pilot tested by students and staff at Harokopio University and by citizens in some of the case study areas. More specifically, the first version of the social capital questionnaire was pilot tested in a convenience sample of 42 men and women, 19-75 years old who had completed different levels of education. The main purpose of this process was to establish the clarity and comprehension of the questions and instructions. The final survey has been carried out throughout the mountainous areas of Pilion and Zagori and, as was expected, this survey provides the main empirical basis for the study. The final questionnaire contained 102 closed-type questions which are divided into nine different sections and provide information about the characteristics of the residents questioned in each of the study areas as well as robust evidence about the household members' participation in various types of social organizations and informal networks, and the range of contributions that the individual gives and receives from them. Furthermore, it provides information about the citizen's trust towards neighbours, it examines how these perceptions have changed over time and gives evidence regarding the citizens' collective action and cooperation as well as their access to information and communication infrastructure. It also provides information about the nature and the range of differences and mechanisms, which threaten the social cohesion and exclude some population groups from key public services. At the same time, there is some evidence about the individuals' empowerment and political action and the dynamics of social innovation in the two case study areas. The research sample consisted of 318 individuals, aged 15 years (194 of whom were residents in the Prefecture of Magnesia, and 124 were residents in the Prefecture of Ioannina).

Care was taken to obtain a cross-sectional sample of adults in each area. The sample was obtained with the assistance of the staff of registry offices in each municipality and community of those selected to take part in the survey. Each registry office was given detailed instructions and assistance in order to obtain a local sample that was a broad cross-section of adults in each community. Actual methods varied in each area, depending on its specific characteristics, but in all cases, a proportion of the sample was obtained from a door-knocking procedure modelled on the census collection procedure. Some other methods to access people also included setting up stalls in public places such as coffee shops and approaching local community centres such as central squares, schools and local workplaces. Although it was not representative of the whole Greek population, the sample was distributed across different ages, educational levels, income categories, and sources of income.

\subsection{Data analysis}

The questionnaires were analyzed, using descriptive statistics and factor analysis. Factor analysis was used to identify the elements of social capital and also to determine which questions were related to social capital and which ones were not. A hierarchical factor analysis was carried out using SPSS 13 package. The 
factor analysis was conducted to establish the factors of the social capital questionnaire and to compare its structure with that found in the Australian sample (Onyx and Bullen [12]). There were 102 social capital items in the original questionnaire. Based on the work of Onyx \& Bullen we finally used 35 of the original 102 items. According to Sapnas and Zeller (2002), a sample size between 50 and 100 was adequate to evaluate the psychometric properties of social science questionnaires (Kritsotakis et al. [13]). By this means, a set of oblique factors may be identified and correlations between them computed. The analysis permitted the identification of a set of specific factors that might identify the separate components of social capital.

\section{Some first findings}

\subsection{Socio-demographic and economic characteristics of the sample in the two case study areas}

The sample comprised 318 citizens aged 16 to 73 in the area of Pilion and 23 to 82 years old in the area of Zagori. Of the total sample, $60 \%$ in the mountainous area of Pilion were female and the average age was 39 , with a standard deviation of 12 , while in the mountainous area of Zagori $62 \%$ were male and the average age was 44 , with a standard deviation 16 . With regard to family status, most of the individuals in the area of Pilion were married (70.6\%). On the other hand, the majority of the citizens in the area of Zagori were unmarried (51.6\%). Also in the area of Pilion $11 \%$ of the total sample had university qualifications, whereas $29 \%$ had not even managed to finish high school, while in the area of Zagori $14 \%$ had university qualifications and $27 \%$ had less than high school qualifications. The respective percentages for the Zagori area were $14 \%$ and $27 \%$. Twenty four percent of the sample in the area of Pilion had an annual family income ranged from $€ 17,610$ to $€ 29,347$, while in the area of Zagori twenty one percent of the sample had an annual family income ranged from $€ 8,806$ to $€ 11,739$. This particularly low income is due to the fact that most of the respondents, in this area, are economically dependent on tourism activities, which is characterised by seasonality. Furthermore, most of the respondents in the mountainous area of Pilion were permanent residents who had lived in the area an average of 31 to 40 years, while the majority of the residents in the area of Zagori lived the area an average of 21 to 30 year.

\subsection{Results of factor analysis}

Tables 1 presents the most basic statistical sizes of factor analysis, such as the factor loadings of each variable in all the factors and the proportion of total variance that each factor explains. The recognition and the determination of the identity of the main factors were supported in the variables with the higher values of factor loadings. High prices ratings of loadings for one or more variables of factor identified this factor. On the whole, we can say that all the resulted factors have the following characteristics: a) are meaningful in terms of 
Table 1: $\quad$ The results of factor analysis.

\begin{tabular}{|c|c|}
\hline \multicolumn{2}{|c|}{ Variables that best define each factor } \\
\hline Mountain area of Pilion & Mountain area of Zagori \\
\hline \multicolumn{2}{|c|}{ FACTORS } \\
\hline Factor 1: quality of life in the local & Factor 1: quality of life and cohesion in \\
\hline Satisfied with living in this area $(.53)$ & Satisfied with living in this area (.46) \\
\hline Seek mediation for dispute $(.54)$ & Seek mediation for dispute $(.65)$ \\
\hline Feels isolation by the community (.69) & Stranger accepted $(.47)$ \\
\hline Level of cohesion in the community (.54) & Feels isolation by the community (.67) \\
\hline Joined local action in emergency $(.55)$ & Feels empathy from others $(.60)$ \\
\hline Give help when needed (.56) & Level of cohesion in the community $(.58)$ \\
\hline Influence the community quality life (.49) & Get help from friend when needed (.26) \\
\hline & Asks neighbour to help care for child (.61) \\
\hline Factor 2: family and neighbourhood & Visited neighbour (-.50) \\
\hline connections & Importance of relatives relation (.67) \\
\hline Asks neighbour to help care for child (-.49) & Influence the community quality life (.39) \\
\hline Talked to relatives $(.67)$ & \\
\hline Visited relatives $(.75)$ & Factor 2: Tolerance to diversity, \\
\hline Importance of relatives relation $(-.72)$ & $\begin{array}{l}\text { reciprocity and friends } \\
\text { connection }\end{array}$ \\
\hline Factor 3:feeling of trust and reciprocity & Strangers create problems (.69) \\
\hline Feels empathy from others (.43) & Local population willingness for help \\
\hline Most people can be trusted (.57) & others $(.54)$ \\
\hline Local population willingness for help others & Give help when needed (.53) \\
\hline$(.82)$ & Phone friends $(-.62)$ \\
\hline Visited neighbour (-.44) & Visited friends $(-.53)$ \\
\hline & Take initiative in the community (.49) \\
\hline Factor 4: developmental character of the & \\
\hline $\begin{array}{l}\text { local community } \\
\text { Socio-economic character of areas' }\end{array}$ & $\begin{array}{l}\text { Factor 3: family connections, feeling of } \\
\text { safety and information }\end{array}$ \\
\hline development (.46) & Residence place feels like home (-.34) \\
\hline Take initiative in the community $(.53)$ & Workplace feels like home (.47) \\
\hline & Joined local action in emergency (.39) \\
\hline Factor 5: participation in the local & Most people can be trusted (.44) \\
\hline community $\&$ access in the & Talked to relatives $(-.44)$ \\
\hline information & Visited relatives $(-.72)$ \\
\hline Notifying a local problem (.53) & Access information (.53) \\
\hline By helping others you help yourself (-.67) & \\
\hline Cooperation with local citizens (.61) & Factor 4: Solidarity and empowerment \\
\hline Attended community event (.42) & By helping others you help yourself $(.75)$ \\
\hline Access information (.45) & Cooperation with local citizens $(.50)$ \\
\hline & Ability to control life (.67) \\
\hline Factor 6: value of life and feeling of safety & Power to change life (.65) \\
\hline Satisfied with life (.62) & \\
\hline Feels safe in street after dark (.24) & Factor 5: value of life and feeling of safety \\
\hline Strangers create problems $(.37)$ & Satisfied with life $(.70)$ \\
\hline Ability to control life (.37) & Notifying a local problem $(-.57)$ \\
\hline Power to change life (.79) & Feels safe in street after dark (.63) \\
\hline Factor 7: friends and residence place & Factor 6: participation, friend connections \\
\hline $\begin{array}{l}\text { connections } \\
\text { cons }\end{array}$ & and character of the community \\
\hline Residence place feels like home (.30) & development \\
\hline Phone friends $(.57)$ & Attended community event (.58) \\
\hline Importance of friend relation $(-.58)$ & Importance of friend relation $(.53)$ \\
\hline Visited friends $(.71)$ & Active member of local organization (.46) \\
\hline
\end{tabular}


Table 1: $\quad$ Continued.

\begin{tabular}{|l|c|}
\hline \multicolumn{1}{|c|}{ Variables that best define each factor } & \\
\hline \multicolumn{1}{|c|}{ Mountain area of Pilion } & Mountain area of Zagori \\
\hline \multicolumn{1}{|c|}{ FACTORS } \\
\hline \begin{tabular}{c|c} 
Factor 8: work \& friend connections, and \\
tolerance of diversity
\end{tabular} & $\begin{array}{l}\text { Socio-economic character of areas' } \\
\text { development } \\
(-.57)\end{array}$ \\
$\begin{array}{l}\text { Workplace feels like home }(.36) \\
\text { Stranger accepted (.35) } \\
\text { Get help from friend when needed (.46) } \\
\text { Active member of local organization }(.72)\end{array}$ \\
\hline
\end{tabular}

Source: author's elaborations.

the conceptual framework, b) are relatively stable across the two different samples, c) all items included in the factors correlate with the total scale score, d) have eigenvalues greater than 1 and e) all the factors together account for a substantial amount of the variance.

\subsubsection{Results of factor analysis for the mountain area of Pilion}

The factor analysis gave 12 factors that interpret the $100 \%$ of the total variance. The final solution identified eight specific independent factors. The eight factors together accounted for $49.3 \%$ of the total variance. The rest of the factors are not commented because the percentage of variance for each one of them is very small in relation to the globally interpreted variance. For the whole sample in the mountain area of Pilion the Kaiser-Meyer-Olkin measure of sampling adequacy was $61 \%$, which is above the recommended .60 (Kaiser [16]). Also the Bartlett's test of sphericity with a significance level less than 0.5 indicates that there are significant relationships among our variables and that our data are suitable for factor analysis. More specifically, the fit statistics is the following: fit Chi-square 1.751 and $d f 595$. The eight primary factors were first identified with a principal component analysis (varimax normalized). The meaning of each factor can be inferred from the item content. Factor 1 was labelled "Quality of life in the local community" and refers to the cohesive character in the local community and to the willingness of the local population to offer their help when it's necessary. Factor 2 was labelled "family and neighbourhood connections" and is defined by questions such as "do you leave / go away from your local community to visit your relatives?". Factor 3 was labelled "feelings of trust and reciprocity" and is defined by questions such as "do you agree that most people can be trusted?". Factor 4 was labelled "development character of the local community". Factor 5 was labelled "participation in the local community and access to information" and refers to participation in community events and to the ability of the local population to be well informed. Factor 6 was labelled "empowerment and feeling of safety" and is defined by such items as "do you think that you have the power to change your life?". Factor 7 was labelled "friends and place of residence connections" and is defined by questions such as "How much did you talk with 
your friends on the phone last week?". Finally, factor 8 was labelled "work \& friend connections, and tolerance to diversity" and is defined by questions such as "do you think that the strangers are easily accepted by the local population?".

\subsubsection{Results of factor analysis for the mountain area of Zagori}

The factor analysis gave 12 factors that interpret the $100 \%$ of total variance. The final solution identified six specific independent factors. The six factors together accounted for $48.9 \%$ of the total variance. Also for the whole sample in the mountain area of Zagori the Kaiser-Meyer-Olkin measure of sampling adequacy was $55 \%$. Moreover the Bartlett's test of sphericity with a significance level less than 0.5 indicates that there are significant relationships among our variables and that our data are suitable for factor analysis. More specifically, the fit statistics as follows: fit Chi-square 1,958 and $d f$ 595. The six primary factors were first identified with a principal component analysis (varimax normalized). The meaning of each factor can be inferred from the item content. Factor 1 is the most important factor of all, as it interprets the $18,15 \%$ of the variance of the total number of variables that was inserted into the analysis. This factor was labelled "quality of life and cohesion in the local community", as it refers to the main characteristics of the local community that determine its level and quality of life. Factor 2 was labelled "tolerance to diversity, reciprocity and friends connection" and is defined by questions such as "do you think that the strangers create problems in the local community?". Factor 3 was labelled "family connections, feeling of safety and information" and is defined by questions such as "do you go outside your local community to visit your family?". Factor 4 was labelled "solidarity and empowerment" and is defined by questions such as "do you agree that by helping others you help yourself in the long run?". Factor 5 was labelled "value of life and feeling of safety" and is defined by items "if you were to die tomorrow, would you feel satisfied with your life". Finally, factor 6 was labelled "participation, friend connections and character of the community development" and refers to participation in formal community structures.

\section{Discussion}

Social capital is an important parameter for achieving high levels of local development because of the effect it my have on the application and the outcomes of local development policies. Greater social capital suggests a better quality of local governance and an active local community leading to a balanced socio-economic local development. The study examined the profile of the available stock of social capital in two Greek rural areas. Measuring social capital on an individual and on a community level is not that simple and is more complex than envisaged, but it contributes considerably to the endeavour of increasing the understanding of this concept. The measurement of social capital in Greece, and especially in the Greek countryside constitutes a big challenge, considering that the research on social capital is still at an early phase in Greece. During this research we had the unique opportunity to access two different areas on a wide range of indicators of social capital that will help us to understand the 
relationship between their differential socio-economic performance and their available stock of social capital. More specifically, the first case study area, which belongs to the Region of Thessaly, is an area with a relatively "successful" performance and the other area which belongs to the Region of Thessaly is an area with "less successful" economic performance. Our social capital questionnaire has been validated by Australian samples and proved to be a valid and practical tool to measure individual and community level social capital in Greek mountain areas.

Factors analysis produced an eight-factor solution for the mountain area of Pilion, and a six- factor solution for the mountain area of Zagori and appears to offer a reasonable fit to the questions. The first results of the study concluded that these areas have carry different available stock of social capital in quantitative and in qualitative terms, despite the fact that they have quite similar geographical and policy contexts. Nevertheless, a more systematic and detailed presentation of the dimensions of social capital in the two case study areas is needed. The value of different forms of social capital is context dependent. Social capital does not function in a vacuum. It is affected by complements, or reinforces the role of other resources that have relevance to a particular challenge or issue. It is therefore necessary to consider the value of different characteristics of social capital in the context of the specific Greek mountainous rural areas.

Regarding the next step of this study, it will focus on explaining whether the existing stock of social capital determines the socioeconomic progress of a place or the other way round the socioeconomic progress of a place defines the profile of its social capital. In fact, the study will add to the argument that the concept of social capital itself can be used to cover the negative effects that a lack of social and economic resources can have on a community.

\section{References}

[1] Woolock, M., Managing Risk, Shocks, and Opportunity in Developing Economies: The Role of Social Capital, In Gustav Ranis, ed. Dimensions of Development. New Haven, CT: Yale Center for International and Area Studies, pp. 197-212, 1999.

[2] Grootaert, C., \& Van Bastelaer, T., (eds). The Role of Social Capital in Development: An Empirical Assessment. New York: Cambridge University Press, 2002a.

[3] Grootaert, C., \& Van Bastelaer, T., (eds). Understanding and Measuring Social Capital: A Multidisciplinary Tool for Practitioners. Washington D.C.: World Bank, 2002b.

[4] Grootaert, C., Does Social Capital Help the Poor? A Synthesis of Findings from the Local Level Institutions Studies in Bolivia, Burkina Faso, and Indonesia. Local level Institutions Working Paper no 10. The World Bank, Washington DC. 2001.

[5] Ibáñez, A. M., Lindert, K., \& Woolcock, M., Social Capital in Guatemala: A Mixed Methods Analysis. Technical Background Paper No. 12, prepared 
for the Guatemala Poverty Assessment. Washington, D.C.: The World Bank, 2002.

[6] Narayan, D. \& Cassidy, M., A Dimensional Approach to Measuring Social Capital: Development and Validation of Social Capital Inventory. Current Sociology, 49 (2), pp. 49-93, 2001.

[7] Narayan, D. \& Pritchett, L., Cents and Sociability: Household Income and Social Capital in Rural Tanzania. Economic Development and Cultural Change, 47 (4), pp. 871-97, 1999.

[8] World Bank, Guatemala Poverty Assessment. Washington D.C.: World Bank, 2003.

[9] Putnam, R. D., Making Democracy Work: Civic Traditions in Modern Italy. Princeton, NJ: Princeton University Press, 1993.

[10] Knack, S. \& Keefer, P., Does Social Capital Have an Economic Payoff? A Cross-Country Investigation. Quarterly Journal of Economics, 4 (11), pp. 1251-1288, 1997.

[11] Trigilia, C., Social Capital and Local Development. European Journal of Social Theory, 4 (4), pp. 427-442, 2001.

[12] Onyx, J. \& Bullen, P., Measuring social capital in five communities. The Journal of Applied Behavioral Science, 36, pp. 23-42, 2000.

[13] Kritsotakis, G., Koutis, A., Alegakis, A. K. \& Philalithis, A. E. Development of the social capital questionnaire in Greece, Survey in Nursing \& Health, DOI: 10.1002/nur.20250, Published Online: Jan 22 2008, Retrieved on 01/03/2008: from the World Wide Web http://www3.interscience.wiley.com/journal/117871052/issue

[14] Cox, E., A truly civil society. Sydney: Boyer Lectures, Australian Broadcasting Corporation, 1995.

[15] Putnam, R. D., "Tuning In, Tuning Out: The Strange Disappearance of Social Capital in America," 1995 Annual Meeting Highlights, The 1995 Ithiel de Sola Pool Lecture, PS: Political Science and Politics, Vol. 28, No. 4, pp. 664-683 (December 1995), pp. 670-671, 677. Archived at: http://links.jstor.org/sici?sici=10490965\%28199512\%2928\%3A4\%3C664\%3ATITOTS\%3E2.0.CO\%3B2-7

[16] Kaiser, H.F., An index of factorial simplicity. Psychometrika, 39, pp. 3136, 1974. 